\title{
Effective sequestration of levofloxacin from wastewater by biochar-supported manganese dioxide composite: Experimental study and modelling analyses
}

\author{
Abel Adekanmi Adeyi ${ }^{1,2^{\dagger}}$, Nathan Kura Bitrus ${ }^{1}$, Luqman Chuah Abdullah ${ }^{2}$, Lekan Taofeek Popoola ${ }^{1}$, \\ Maureen Chijioke-Okere ${ }^{3}$, Oluwagbenga Olawale Omotara ${ }^{1}$, Shihab Ezzuldin M.Saber ${ }^{2,4}$ \\ ${ }^{1}$ Department of Chemical and Petroleum Engineering, College of Engineering, Afe Babalola University Ado-Ekiti, ABUAD, KM. 8.5, Afe Babalola Way, \\ Ado-Ekiti, Ekiti State, Nigeria \\ ${ }^{2}$ Department of Chemical and Environmental Engineering, Faculty of Engineering, Universiti Putra Malaysia, UPM Serdang 43400, Malaysia \\ ${ }^{3}$ Department of Chemistry, School of Physical Science, Federal University of Technology Owerri (FUTO), PMB 1526 Owerri, Nigeria \\ ${ }^{4}$ North Refineries Company, Ministry of Oil, Iraq
}

Received October 11, 2021 Revised December 01, 2021 Accepted January 03, 2022

\begin{abstract}
Manganese dioxide was laden hooked on biochar sourced from chicken feather to obtain a biochar-supported manganese dioxide (BSM) composite. In order to reduce the costs of acquisition and minimise the disposal of adsorbents, prepared BSM composite were employed in the sequestration of Levofloxacin (LEVO) from aqueous environment. The physico-chemical features and the adsorption mechanisms of prepared BSM, prior and after the adsorption of LEVO molecules were revealed by Scanning Electron Microscopy and Fourier Transform Infrared spectroscopy techniques. The influence of adsorption parameters including BSM dose, initial concentration, temperature and residence time were studied. The removal of LEVO was significantly influenced by all parameters. Equilibrium data has its fitness in the following order: Redlich-Peterson $>$ Langmuir $>$ Freundlich models. The maximum adsorption capacity of BSM for LEVO was $104.13 \mathrm{mg} / \mathrm{g}$. The kinetic analysis indicates best fittings for pseudo-second-order model suggesting chemisorption as controlled mechanism. Besides, liquid film and intra-particle diffusion had a vital influence on the LEVO sequestration process. Exothermic and spontaneous nature of LEVO uptake by BSM was revealed by thermodynamic analysis. The findings suggested that prepared BSM show high sorption capacity, and recyclability potential towards separation of LEVO from contaminated pharmaceutical wastewater.
\end{abstract}

Keywords: Biochar, Chicken feather, Composite, Mechanisms, Levofloxacin, Sequestration

\section{Introduction}

Levofloxacin (LEVO) also known as fluoroquinolones, is an antibiotics drug used for the treatment of transmittable ailments such as genitourinary, gastrointestinal tract, and respiratory infections. Due to the inappropriate treatment of the effluent from pharmaceutical industry, regular consumption of a wide range of pharmaceutical drugs by humans and animals, its mishandling in livestock breeding and incomplete metabolism, disproportionate antibiotics are ex- truded to the environment [1]. Through food and water, living organisms could grip excess antibiotics present in the environment, ensuing in antibiotics resistance. The continuous release of fluoroquinolones into water system, irrespective of its concentration in solution is a potential hazard towards the aquatic ecology and freshwater safety [2].

Presently, several methods have been utilized for the removal of antibiotics including advanced oxidation [3], membrane separation [4], ozonation, photochemical degradation [5], and adsorption
cC (5) This is an Open Access article distributed under the terms of the Creative Commons Attribution Non-Commercial License (http://creativecommons.org/licenses/by-nc/3.0/) which permits unrestricted non-commercial use, distribution, and reproduction in any medium, provided the original work is properly cited. $\dagger$ Corresponding author

E-mail: abeladeyi@abuad.edu.ng

Tel: +2348060921556

ORCID: 0000-0002-6428-0836

Copyright (C) 2023 Korean Society of Environmental Engineers 
processes [6, 7]. Adsorption method is considered as one of the most applicable technologies compared to other technologies cited, due to it low cost, no sludge formation, simple operations [1, 8, 9]. Chitosan, montmorillonite, and graphene-based materials are some of the adsorbents that have been tested for the adsorptive separation of emerging contaminants from water.

Biochar sourced adsorbent recently gained relevance and researchers focus due to economic and sustainability factor [10-12]. Biochar is a product rich in carbon, and prepared by heating or pyrolysis of biomass in absence or presence of little air at relatively low temperature (below $700^{\circ} \mathrm{C}$ ) [13]. It can be produced from several kinds of organic raw materials especially wastes such as municipal wastes, solid food production wastes, agricultural and livestock wastes $[14,15]$. Besides, biochars are less expensive than conventional activated carbons, which further enhances their attractiveness. For instance, the cost of ACs ranges from $\$ 1,100-\$ 1,700$ per ton, while $\$ 350-\$ 1,200$ per ton is the price ranges for production of biochars [16]. In this research, authors explored the adsorption capacity of biochar derived from chicken feather waste. Chicken feather is regards as a waste material, emanates from food industry and its disposal often constitute nuisance to the environment [17-19].

To achieve the aims of low cost, sustainability and environmental benefits, chicken feather is transformed into biochar, supported with manganese dioxide to form a composite for antibiotics removal from wastewater. Biochar is a product rich in carbon, and appears promising as adsorptive solid employed in the treatment contaminants-bearing wastewater. It is porous in structure, large and complex surface area, as well as its richness in surface functional groups, which possessed polyelectrolyte feature capable as ion exchangers [20, 21]. However, the adsorption capacity of original biochar can be improved further via modification physically and or chemically.

Manganese oxide nanoparticles have been used as an adsorbent in the past [22-26]. Because of their exceptional polycrystalline structure, $\mathrm{MnOx}$ particles have a large specific surface area and excellent adsorption properties. However, nano-sized MnOx particles easily clump together, limited their usefulness as adsorbents [27]. This research will establish a simple, low-cost method of loading $\mathrm{MnOx}$ nanoparticles onto chicken feather biochar for the separation of LEVO antibiotics from aqueous solution. This approach not only overcomes the agglomeration issue, but it also increases the efficacy of the nano-metal oxide ( $\mathrm{MnOx}$ ) in assisting biochar in pollution removal. Experiment data was also represented as dynamic and equilibrium models, as well as the thermodynamic analyses.

\section{Materials and Methods}

\subsection{Materials, Reagents and Levofloxacin}

The poultry waste used was obtained from Afe Babalola University's cafeteria. Manganese dioxide $\left(\mathrm{MnO}_{2}, 99.0 \%\right.$ purity), sodium hydroxide $(\mathrm{NaOH})$, and hydrochloric acid $(\mathrm{HCl})$ were all supplied by Sigma Aldrich (USA). The antibiotic drug used for the solution was levofloxacin (LEVO $\left(\mathrm{C}_{18} \mathrm{H}_{20} \mathrm{FN}_{3} \mathrm{O}_{4} ; 361.37 \mathrm{mg} / \mathrm{mol}\right.$ )) (Aspen Pharmacare Nigeria Ltd).

\subsection{Biochar-supported Manganese Dioxide (BSM) Composites Synthesis}

The waste chicken feathers were washed with distilled water and detergents to remove attached dirt materials, and rinsed properly. Thereafter, feathers were left in open air for $48 \mathrm{~h}$, to get rid of odours. A scissor was used to cut the dried feathers to exclude rachis. $30 \mathrm{~g}$ of small size barbs feather were soaked in $1.0 \mathrm{M} \mathrm{NaOH}$ for $72 \mathrm{~h}$ in a water bath operating at $50^{\circ} \mathrm{C}$. The impregnated feathers were filtered and then rinsed severally with double distilled water to eliminate excess $\mathrm{NaOH}$ and dried at ambient temperature. Alkaline impregnated chicken feathers (20 g) were carbonized in the furnace at $200^{\circ} \mathrm{C}$ for $1.5 \mathrm{~h}$. The resulting biochar removed from the furnace and left for $2 \mathrm{~h}$ to cool, then crushed and sieved using $100 \mu \mathrm{m}$ mesh to obtained uniform powdered chicken feather biochar.

For biochar-supported manganese dioxide synthesis, $1 \mathrm{~g}$ of $\mathrm{MnO}_{2}$, $10 \mathrm{~mL}$ ethanol and $70 \mathrm{~mL}$ of double distilled water were added into $250 \mathrm{~mL}$ conical flask, and then the mixture was stirred vigorously for $2 \mathrm{~h}$. Then, $5 \mathrm{~g}$ of prepared chicken feather biochar was added to the mixture, and stirring continue for another $0.5 \mathrm{~h}$ to ensure that the reaction complete. The mixture was left overnight at room temperature for aging. Thereafter, the mixture was filtered and washed several times with double distilled water, and dried in a vacuum at $100^{\circ} \mathrm{C}$ for $6 \mathrm{~h}$. This sample was denoted as biochar supported manganese dioxide (BSM) composite.

\subsection{Instrumentation}

Fourier-transform infrared spectroscopy (FTIR) of BSM (prior to and after adsorption) was recorded on Perkin Elmer 1750X spectrometer (U.K.) using potassium bromide $(\mathrm{KBr})$ pellet that operated within the resolution range of 4,000-400 $\mathrm{cm}^{-1}$ under atmospheric circumstances with a resolution of $1 \mathrm{~cm}^{-1}$. Scanning electron microscope (SEM) micrographs were acquired also using a Hitachi $\mathrm{S}-3400 \mathrm{~N}$ instrument (Japan). Samples were coated in $\mathrm{Au} / \mathrm{Pd}$ film prior to analysis.

\subsection{Batch Adsorption Experiments}

Every adsorption experiment was performed with duplicate samples in each group on a magnetic stirrer at constant temperature and $100 \mathrm{rpm}$, and average data were recorded for analysis. The concentration of LEVO antibiotics after sequestration was measured by UV spectrophotometry (Lambda 35PerkinElmer Life and Analytical Science, Singapore 139959, Singapore) at $280 \mathrm{~nm}$. The calculation of the extent of LEVO uptake and capacities of BSM composite are performed using Eq. (1) and (2), respectively:

$$
\begin{gathered}
E=\frac{C_{o}-C_{e}}{C_{o}} \times 100 \% \\
q_{e}=V \frac{C_{o}-C_{e}}{m_{B S M}}
\end{gathered}
$$

Where $E(\%)$ is the LEVO removal extent from the aqueous solution; $C_{o}$ and $C_{e}$ are the initial and residual LEVO concentration remaining in solution $(\mathrm{mg} / \mathrm{L})$, respectively; $q_{e}$ is the sorption capacity 
of BSM (mg/g); $V$ is the solution volume (mL); and $m_{B S M}$ is the quantity of BSM adsorbent used (g).

In the temperature range of 25 to $60^{\circ} \mathrm{C}, 0.1 \mathrm{~g}$ of $\mathrm{BSM}$ was added to $50 \mathrm{~mL}$ of LEVO antibiotics solution ( $50 \mathrm{mg} / \mathrm{L}$ ) into a $250 \mathrm{~mL}$ Erlenmeyer flask. Under similar adsorption parameters condition (pH- 7.7, BSM dose- $0.1 \mathrm{~g}$, contact time- $60 \mathrm{~min}$ ), the LEVO removal percentage were compared at $25,35,45$, and $60^{\circ} \mathrm{C}$.

Under optimum temperature, 0.05, 0.1, 0.2, 0.3, 0.4 and 0.5 $\mathrm{g}$ of BSM and $50 \mathrm{~mL}$ of LEVO solutions $(50 \mathrm{mg} / \mathrm{L})$ were added to a $250 \mathrm{~mL}$ flask, and stirred for $60 \mathrm{~min}$ at $100 \mathrm{rpm}$. Furthermore, $0.1 \mathrm{~g}$ of BSM was added to $50 \mathrm{~mL}$ of LEVO solution $(80 \mathrm{mg} / \mathrm{L})$ in a $250 \mathrm{~mL}$ flask and stirred at optimum temperature, and solution $\mathrm{pH}$. Then, samples were drawn at the corresponding reaction time $(5,10,15,30,60,90$, and $120 \mathrm{~min})$. The pseudo-first-order (PFO (Eq. (3)), and the pseudo-second-order (Eq. (4)) [28] kinetic models, were employed to analyzed the adsorption mechanism of LEVO by BSM. In addition, liquid film diffusion (Eq. (5)) [29] and intra-particle diffusion (Eq. (6)) [30] models were used to underscore the role of diffusion in the LEVO adsorption rate onto the BSM surface.

$$
\begin{gathered}
q_{t}=q_{e}\left(1-e^{-k_{1} t}\right) \\
q_{t}=\frac{k_{2} q_{e}^{2} t}{1+k_{2} q_{e} t} \\
\operatorname{Ln}(-F)=-k_{l f d} t \\
q_{t}=k_{i p d} t^{1 / 2}+C_{i}
\end{gathered}
$$

Where $q_{t}$ and $q_{e}$ are sorption capacities (mg/g) of BSM at time $t$, and at equilibrium, respectively; $k_{1}$ and $k_{2}$ are the adsorption rate constants for PFO, and PSO kinetic model, respectively. $F=q_{t} / q_{e}$ represent the fractional equilibrium attainment; $k_{l f d}$ and $k_{i p d}$ denote respectively, liquid film diffusion rate constant and intra-particle diffusion rate constant. Intercept $C_{i}$ is the boundary layer thickness effect.

At the LEVO solution $\mathrm{pH}$, optimum BSM dosage and temperature, $50 \mathrm{~mL}$ of LEVO solutions with initial concentrations 10, 20, 40, $50,80,100,120$, and $150 \mathrm{mg} / \mathrm{L}$, respectively, to $250 \mathrm{~mL}$ flasks and then stirred for $120 \mathrm{~min}$. Two parameters models (Langmuir and Freundlich), and three parameters isotherm (Redlich-Peterson) were employed to unraveled the LEVO entrapment mechanism. The isotherm formulas are:

$$
\begin{gathered}
q_{e}=\frac{q_{m} K_{L} C_{e}}{1+K_{L} C_{e}} \\
q_{e}=K_{F} C_{e}^{1 / n} \\
q_{e}=\frac{K_{R P} C_{e}}{1+\alpha C_{e}^{\beta}}
\end{gathered}
$$

Where $q_{m}$ is the maximum monolayer adsorption capacity (mg/g) and $K_{L}$ Langmuir constant associated with the free energy of adsorption (L/mg); $K_{F}$ and $n$ are respectively Freundlich constants related to bonding energy $(\mathrm{L} / \mathrm{mg}$ ) and adsorption intensity and heterogeneity; $K_{R P}(\mathrm{~L} / \mathrm{g}), \alpha(\mathrm{L} / \mathrm{mg})^{\beta}$, and $\beta$ represent isotherm constants. The model is identical to Freundlich model at high concentration according to [31].

For regeneration/reusability study, $2.5 \mathrm{~g}$ of BSM composite was subjected to five consecutive cycles of adsorption-desorption, in order to investigate the reusability of the prepared adsorbent. In a $250 \mathrm{~mL}$ flask, the adsorbent was combined with $100 \mathrm{~mL}$ of LEVO solution (300 mg/L). At $100 \mathrm{rpm}$ and room temperature, the mixture was stirred. The BSM solids were separated by filtration after 3 h. The filtrate was analyzed to determine the quantity of LEVO adsorbed. Then, for LEVO elution, the BSM was added to a 50 $\mathrm{mL}$ mixture of ethanol and double distilled water (4:1, v/v). The regenerated BSM sample was rinsed with double distilled water and dried over night at $50^{\circ} \mathrm{C}$. The regeneration efficiency $\left(R_{n}\right)$ was calculated with Eq. (10):

$$
R_{n}=\frac{q_{e, n}}{q_{e, o}} \times 100 \%
$$

Where $n$ is the number of times the BSM was regenerated, $q_{e, n}$ (mg/g) represent the sorption capacity of the regenerated BSM for $n$ time, and $q_{e, o}(\mathrm{mg} / \mathrm{g})$, the sorption capacity of fresh BSM.

\section{Results and Discussion}

\subsection{Biochar Supported Manganese Dioxide (BSM) Composite Characterization}

FTIR and SEM techniques were used to characterize the BSM composite adsorbent. The FTIR approach was utilized to examine and identify the functional groups contained in the biochar supported manganese dioxide (BSM) composite, as well as to assess post-adsorption chemical structural alterations. Fig. 1 shows the FTIR spectra and absorption bands of the two materials in the region of $4,000-500 \mathrm{~cm}^{-1}$. In the infrared spectrum of BSM, the characteristics peaks at 1,071 and $1,726 \mathrm{~cm}^{-1}$ are assigned to epoxide rings and carbonyl groups, respectively. The characteristic absorption peaks of hydroxyl $(\mathrm{O}-\mathrm{H})$ and amine $(\mathrm{N}-\mathrm{H})$ stretching vibrations appears at 3,482 and $3,728 \mathrm{~cm}^{-1}[9,17,19]$. In the spectrum of LEVO-loaded BSM, the above identified functional groups shifted or reduced. This indicated that the presence of these characteristic functional groups at BSM surface possibly aids LEVO entrapment from aqueous solution.

Fig. 2 shows scanning electron micrographs of the BSM and LEVO-loaded BSM composites taken using a scanning electron microscope (SEM). Non-uniform and rough surface were identified on the image of unloaded BSM solids (Fig. 2(a)). Post LEVO antibiotics sequestration, a notable alteration is detected in the structure of BSM (Fig. 2(b)). The unoccupied pores seem to be filled and covered with cloud of LEVO molecules, probably a confirmation that localized concentration of bound LEVO and heterogeneous polar functional groups distribution on the BSM composite surface. 


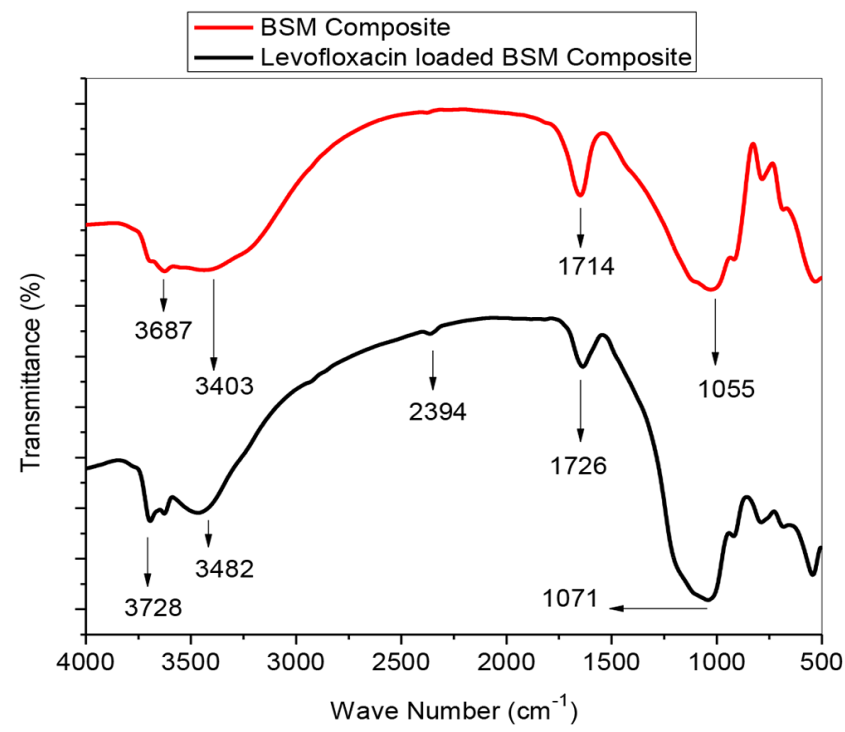

Fig. 1. FTIR spectra of BSM and LEVO-loaded BSM adsorbents.
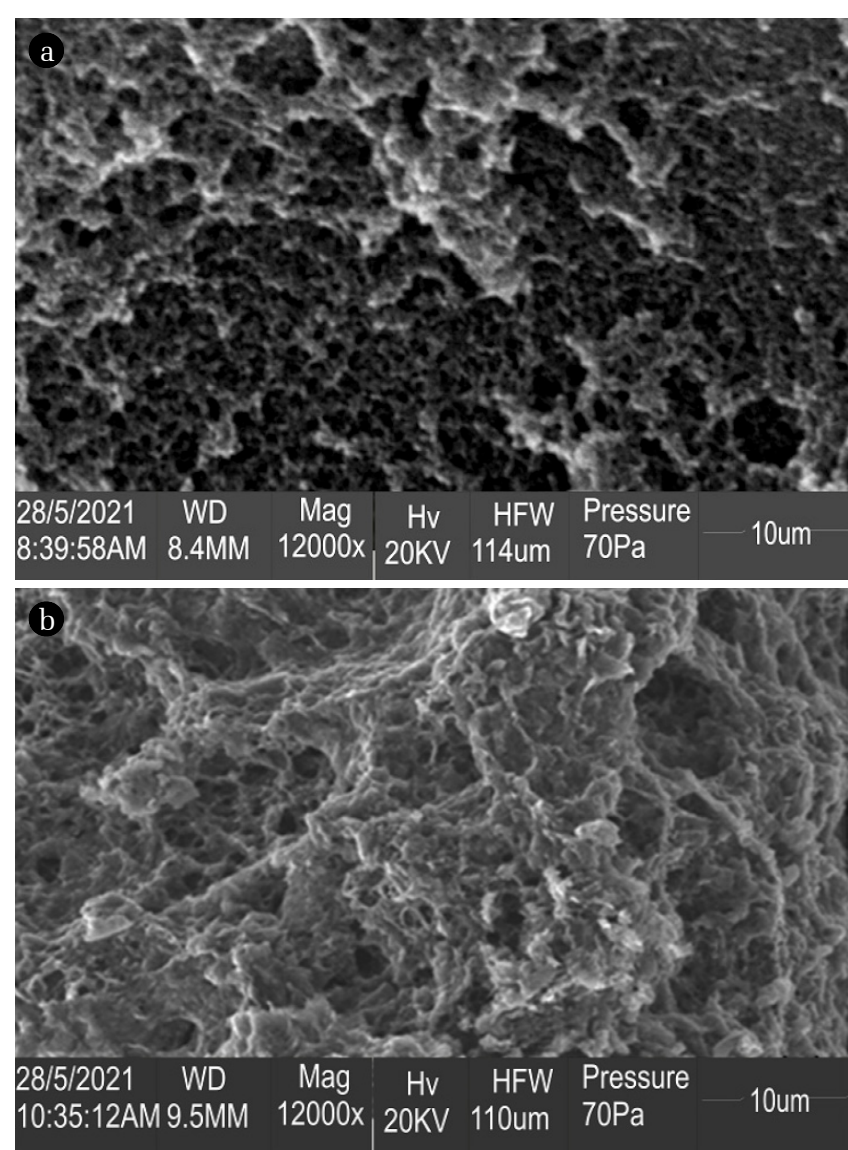

Fig. 2. SEM micrographs of (a) modified chicken feather, and (b) LEVO loaded modified chicken feather.

Similar findings was reported by Sekulic and group [32] for the adsorption of pharmaceuticals (sulfamethoxazole, carbamazepine and ketoprofen).

\subsection{Evaluation of Activated Carbon Efficiency}

\subsubsection{Influence of adsorbent dose}

The effect of BSM dose was examined in the range of 0.05-0.5 g adsorbent while all other parameters were kept constant $(\mathrm{pH}$ : 7.7, initial LEVO concentration: $50 \mathrm{mg} / \mathrm{L}$, contact time: $60 \mathrm{~min}$, temperature: $25 \pm 1^{\circ} \mathrm{C}$ ), with the findings shown in Fig. 3. The LEVO removal rate rose with increasing adsorbent dosage and reached a maximum at $0.1 \mathrm{~g}$ dose when the BSM dose was increased from 0.05 to $0.5 \mathrm{~g}$ under constant conditions. This increase is due to the greater surface and pore volume of adsorbent that is available at higher doses, resulting in more functional groups and adsorption sites that are beneficial to improving LEVO removal effectiveness [1]. As a result, the adsorbent dose of $0.1 \mathrm{~g}$ was chosen in the next studies, as no significant variations in the extent of LEVO removal rate were detected as the BSM quantity was increased.

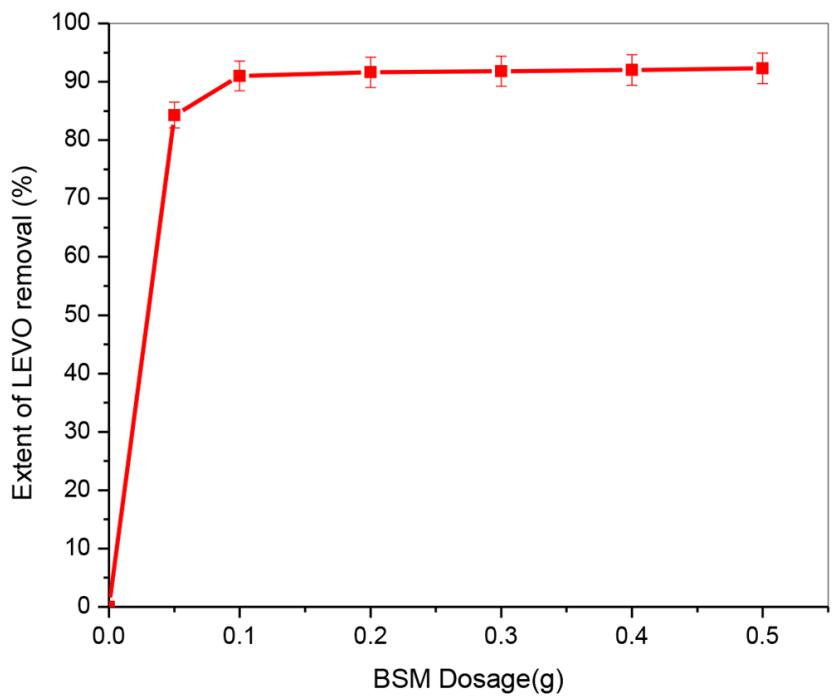

Fig. 3. Effect of adsorbent dosage on LEVO uptake. $(\mathrm{pH}=7.7$, Co: $50 \mathrm{mg} / \mathrm{L}$; temperature: $298 \mathrm{~K}$; time: $60 \mathrm{~min}$ )

\subsubsection{Influence of LEVO concentration}

By adjusting the initial LEVO concentration in the test solution from 10 to $150 \mathrm{mg} / \mathrm{L}$ while maintaining all other parameters constant (pH: 7.7, BSM dose: $0.1 \mathrm{~g}$, contact time: $60 \mathrm{~min}$, temperature: $25 \pm 1^{\circ} \mathrm{C}$ ), the effect of solution concentration was investigated. The amount of LEVO adsorbed increased as the initial concentration was increased, eventually reaching saturation at higher concentrations, as shown in Fig. S1. The increased amount of LEVO adsorbed by the adsorbents with increasing initial LEVO concentration could be owing to an increase in interactions between LEVO and BSM, which involves active sites with escalating affinity for the LEVO species up to saturation point. Thereafter, the system attains saturation point, increase in the initial solution concentration showed significant reduction in the extent of LEVO antibiotics adsorbed due to a decrease in the number of active sites compared with higher LEVO concentration [33].

\subsubsection{Influence of solution temperature}

Environmental temperature often plays a vital role in the chemical 
reaction operation. Therefore, influence of temperature on the removal efficiency of LEVO by adsorption onto BSM is presented in Fig. S2. When the temperature was varied from 25 to $60^{\circ} \mathrm{C}$, the adsorption efficiency decreased from 95 to $85 \%$, demonstrating an exothermic process. Due to increasing solubility of LEVO in the solution, the solute became difficult to adsorb. Furthermore, increased temperature caused existing intermolecular hydrogen bonds between BSM and LEVO to break. The weakening of the adsorptive forces between the adsorbate molecules and the surface-active sites of the adsorbent, which was discovered to have a key contribution to the adsorption process, could possibly explain the decrease in LEVO adsorption with increasing temperature [34]. The LEVO molecules diffusion onto the core of BSM needs no extra thermal energy, and ambient temperature $\left(25 \pm 2^{\circ} \mathrm{C}\right)$ was used at the optimum temperature for further adsorption experiments.

\subsubsection{Influence of resident time}

Fig. S3 shows the effect of contact time on LEVO removal efficiency by adsorption onto a BSM sample. Adsorption studies were carried out at various contact times while all other variables remained constant $(\mathrm{pH}=7.7$, LEVO concentration $80 \mathrm{mg} / \mathrm{L}$, adsorbent dose $0.1 \mathrm{~g}$, temperature $25 \pm 2^{\circ} \mathrm{C}$ ). Fig. S3 shows a rapid rise in LEVO removal efficiency during the first $20 \mathrm{~min}$, which could be attribute to a strong driving force that increases LEVO particle mass transfer to the BSM adsorbent. Furthermore, in the early stages of adsorption, the availability of a greater surface area as well as more empty active sites improved sorption effectiveness $[35,36]$. The adsorption rapidly increased with increasing contact time until equilibrium was reached at $60 \mathrm{~min}$, with 98.5 percent LEVO elimination. Beyond $60 \mathrm{~min}$, extent of LEVO entrapment is constant. Therefore, the optimum contact time was selected as $60 \mathrm{~min}$ for further experimentations.

\subsection{Adsorption Isotherm Models}

Adsorption isotherm as a key design tool which shows the association between adsorbate and adsorbent at equilibrium, Langmuir, Freundlich and Redlich-Peterson models were employed as illustrated in Fig. 4. According to square sum of error (SSE) values for the non-linear fitting (Table 1), Redlich-Peterson showed the best fitting follow by Langmuir, and Freundlich came last. This result signified that the LEVO sequestration by BSM is a mix of both heterogeneous and homogeneous and or monolayer and multilayer adsorption systems [37-39]. Furthermore, the SSE value of the Langmuir model is lesser than that of Freundlich model. It is an indication that LEVO uptake onto BSM is largely dominated by monolayer interactions [40]. However, LEVO entrapment mechanism unto BSM surface include chemisorption, precipitation, and ion exchange.

The value $\beta$ and $n$ respectively for Redlich-Peterson and Freundlich models fall between 1 and 10, is an indicative assurance that LEVO antibiotic entrapment is favourable, and the prepared BSM composite is good. Strong bond exists between LEVO molecule and BSM. The maximum sorption capacity of LEVO predicted by Langmuir isotherm was up to $104.13 \mathrm{mg} / \mathrm{g}$, which is favourably higher compared to other adsorbents reported in Table 2.

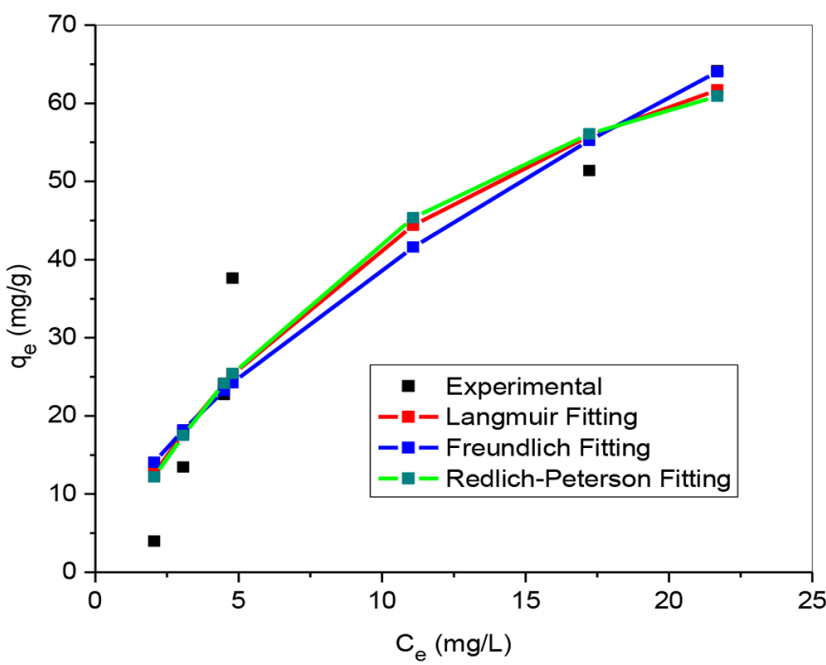

Fig. 4. Adsorption isotherms of LEVO on BSM composite. (Dosage: $0.1 \mathrm{~g}$, temperature: $\left.298 \mathrm{~K}, \mathrm{C}_{\mathrm{o}}: 10-150 \mathrm{mg} / \mathrm{L}\right)$

Table 1. Nonlinear Adsorption Constants for the Applied Two-parameter and Three-parameter Isotherms

\begin{tabular}{lccccc}
\hline Models & \multicolumn{5}{c}{ Parameters } \\
\hline \multirow{2}{*}{ Langmuir } & $q_{m}(\mathrm{mg} / \mathrm{g})$ & $K_{L}(\mathrm{~L} / \mathrm{mg})$ & $S S E$ & $R^{2}$ \\
& 104.13 & 0.0671 & & 271.85 & 0.9648 \\
\hline \multirow{2}{*}{ Freundlich } & $n$ & $K_{F}(\mathrm{~L} / \mathrm{mg})$ & & $S S E$ & $R^{2}$ \\
& 1.5548 & 8.8516 & & 326.35 & 0.8976 \\
\hline Redlich- & $K_{R P}(\mathrm{~L} / \mathrm{g})$ & $\alpha(\mathrm{L} / \mathrm{mg})^{\beta}$ & $\beta$ & $S S E$ & $R^{2}$ \\
Peterson & 6.3507 & 0.0285 & 1.2323 & 268.20 & 0.9775 \\
\hline
\end{tabular}

Table 2. Adsorption Capacity of Agricultural Waste and by Products

\begin{tabular}{|c|c|c|}
\hline Adsorbent & $\begin{array}{c}q_{m} \\
(\mathrm{mg} / \mathrm{g})\end{array}$ & References \\
\hline Magnesium supported biochar & 25.2 & [41] \\
\hline Alumina-doped coconut coir charcoal & 1.15 & [42] \\
\hline Iron-pillared clay minerals & 72.09 & [43] \\
\hline Iron based MOFs (MIL-100(Fe)) & 87.34 & [44] \\
\hline $\mathrm{Chi}-\mathrm{SiO}_{2} / \mathrm{Fe}_{3} \mathrm{O}_{4}$ nanoparticles & 100.74 & [45] \\
\hline Powdered zeolite (FAU-1) & 31.32 & [46] \\
\hline BSM & 104.13 & Current study \\
\hline
\end{tabular}

\subsection{Kinetic Study}

Kinetic study is relevant in the evaluation of adsorbent quality, efficiency, adsorption reaction rate and adsorbate sequestration mechanism. The relationship between LEVO uptake and contact time is depicts in Fig. S4. The corresponding correlation coefficients $\left(\mathrm{R}^{2}\right)$ value is used to assess the validity of the PFO and PSO models, and the experimental and calculated kinetic data are shown in Table 3. The PFO model's calculated adsorption capacity $q_{e(c a l)}$ differs greatly from experimental values $q_{e(\exp )}$, revealing its inadequacy in describing the adsorption system. The correlation coefficients, $R^{2}$ had a value of 0.7107 , and this can be as low compared to PSO model. This implies that PFO model was not suitable to 
Table 3. Kinetic Parameters and Correlation Coefficients of LEVO onto BSM

\begin{tabular}{|c|c|c|c|c|}
\hline \multicolumn{2}{|c|}{ Model } & \multicolumn{3}{|c|}{ Parameters } \\
\hline PFO & $k_{1}\left(\min ^{-1}\right)$ & $q_{e(\exp )}(\mathrm{mg} / \mathrm{g})$ & $q_{e(c a l)}(\mathrm{mg} / \mathrm{g})$ & $R^{2}$ \\
\hline $80 \mathrm{mg} / \mathrm{L}$ & 0.0305 & 37.61 & 7.26 & 0.7107 \\
\hline PSO & $k_{2}(\mathrm{~g} / \mathrm{mg} \cdot \min )$ & $q_{e(\exp )}(\mathrm{mg} / \mathrm{g})$ & $q_{e(c a l)}(\mathrm{mg} / \mathrm{g})$ & $R^{2}$ \\
\hline $80 \mathrm{mg} / \mathrm{L}$ & 0.0096 & 37.61 & 40.00 & 0.9989 \\
\hline
\end{tabular}

describe the adsorption mechanism of LEVO to the BSM. The PSO kinetic model's $\mathrm{R}^{2}$ value was very high, and the estimated adsorption capacity value $q_{\text {e(cal) }}$ in Table 3 was very close to the experimental $q_{e(\mathrm{exp})}$, implying that the PSO model may be used to represent LEVO adsorption rate data onto BSM composite. Thus, the entrapment of LEVO molecule unto BSM surface was via chemisorption. Same deductions have been reported by [33, 41, 47], toward antibiotics removal from aqueous environment.

Adsorption kinetic data were further analysed with liquid film and intra-particle diffusion models as illustrated in Fig. S5, and corresponding diffusion model parameters are presented in Table S1. None of the figures has zero intercept, suggest that neither liquid film diffusion nor intra-particle diffusion is solely dominant or controlled LEVO sequestration rates. However, the regression results of both model fittings revealed that liquid film diffusion majorly limiting the removal process of LEVO antibiotic unto BSM, since it had the higher value of R-square (0.9256) as captured in Table S1. Besides, kinetic and equilibrium analyses show that the LEVO sorption process is complex and is controlled by more than two mechanisms. This complexity may be associated to the nature of BSM composite-presence of diverse functional groups, which propelled difference diffusion models as a result of multiple adsorbate-adsorbent interactions. Similar phenomenon was reported by Elamin and group 2021, in the adsorption of paracetamol and metformin from liquid phase [48].

\subsection{Thermodynamics Analyses}

In order to better understand LEVO adsorption behaviour, the effect of temperature on the trapping of LEVO molecules by BSM composite was investigated thermodynamically. The following equations 11-13 were used to compute thermodynamic parameters such as Gibbs free energy $\left(\Delta G^{o}\right)$, enthalpy $\left(\Delta H^{\circ}\right)$, and entropy $\left(\Delta S^{o}\right)$. Where $T(\mathrm{~K})$ is absolute temperature, $K_{d}\left(\mathrm{~L} \mathrm{~g} \mathrm{~g}^{-1}\right)$ is the adsorption equilibrium distribution constant, and $R$ is the gas constant $(8.314 \mathrm{~J}$ $\left.\mathrm{mol}^{-1} \mathrm{~K}\right)$.

$$
\begin{gathered}
\Delta G^{o}=\Delta H^{o}-T \Delta S^{o} \\
\Delta G^{o}=-R T \ln K_{d} \\
\ln K_{d}=\ln \frac{q_{e}}{C_{e}}=\frac{\Delta S^{o}}{R}-\frac{\Delta H^{o}}{R T}
\end{gathered}
$$

Table 4 shows the computed Gibb's free energy change for LEVO uptake adsorption at all of the temperatures examined, as well as the calculated values of the $\Delta \mathrm{H}^{\circ}$ and $\Delta \mathrm{S}^{\circ}$. The negative values of $\mathrm{H}^{\circ}\left(-28.18^{\circ} \mathrm{C}\right)$ confirm that the process is exothermic and that
Table 4. Thermodynamic Parameters for Adsorption of LEVO

\begin{tabular}{lcccc}
\hline $\begin{array}{l}\text { Temperature } \\
T(\mathbf{K})\end{array}$ & $K_{d}$ & $\begin{array}{c}\Delta G^{o} \\
(\mathbf{k J} / \mathbf{m o l})\end{array}$ & $\begin{array}{c}\text { Parameter } \\
\Delta H^{o}(\mathbf{K J} / \mathbf{m o l})\end{array}$ & $\begin{array}{c}\Delta S^{o} \\
\mathbf{J} / \mathbf{m o l ~ K})\end{array}$ \\
\hline 298 & 7.86 & -51.89 & -28.18 & -77.152 \\
308 & 6.14 & -44.17 & - & - \\
318 & 3.69 & -36.45 & - & - \\
333 & 2.50 & -24.88 & - & - \\
\hline
\end{tabular}

the LEVO adsorption process is not favored at higher temperatures. The fact that $\Delta \mathrm{G}^{\circ}$ was negative throughout the adsorption period implies that LEVO adsorption was spontaneous and possible at all of the temperatures tested. Finally, the negative $\Delta S^{\circ}$ values indicate that the solid-solution interface has less unpredictability $[49,50]$.

The regeneration ability of BSM adsorbent is one of the vital criteria to evaluate its industrial application feasibility. Solvent desorption approach was performed by addition of a mixed solution of ethanol and double distilled water $(4: 1, \mathrm{v} / \mathrm{v})$ to saturated BSM. The result as presented in Fig. S6, showed that the percentage LEVO uptake is higher than $78 \%$ after five successive adsorption-desorption cycles with respect to the first fresh cycle. Hence, BSM composite demonstrate multiple usage towards separation of LEVO antibiotics from liquid environment.

\section{Conclusions}

By loading manganese dioxide on waste chicken feather charcoal, a biochar-supported manganese dioxide (BSM) composite was prepared in this study. In a batch mode using the OVAT (One Variable at a Time) approach, the prepared BSM composite was utilized as an adsorbent for the adsorptive removal of LEVO antibiotic from aqueous solution. Under constant conditions, the removal of LEVO was increased by increasing the adsorbent dose from 0.05 to $0.5 \mathrm{~g}$; the LEVO removal rate rose with increasing adsorbent dosage, with the optimum at $0.1 \mathrm{~g}$ dose. The pseudo-second order model was found to best describe the adsorption kinetics of LEVO on BSM, implying that chemisorption is the most likely route for LEVO removal. The Redlich-Peterson three parameter isotherm model, particularly represents the mixture of monolayer and multilayer adsorption mechanisms, best suited the equilibrium isotherm data. The Langmuir maximum adsorption capacity of BSM towards LEVO is $104.13 \mathrm{mg} / \mathrm{g}$. The exothermic and spontaneous nature of the adsorption process was demonstrated by the thermodynamic parameter values. Because of its high sorption capacity and recyclability, BSM should be tested in a larger scale as functional and quality material for the adsorptive removal of LEVO from wastewater.

\section{Acknowledgments}

The authors thankfully acknowledge Aare Afe Babalola, and Chemical and Petroleum Engineering Department of Afe Babalola University Ado-Ekiti (ABUAD), Ekiti State, Nigeria for provision of conducive environment for this research. 


\section{Conflict-of-Interest}

The authors hereby declare that there is no conflict of interest regarding the publication of this article.

\section{Author Contributions}

A.A.A. (Ph.D), N.K.B. (Master student) and O.O.O. (M.Sc./Tutor) performed all the experimental and involved in data analysis. L.C.A. (Professor), L.T.P. (Senior Lecturer), M.C. (Senior Lecturer) and O.O.O. (M.Sc.) and S.E.M. (Ph.D) contributed reagents, materials and analysis tools. All authors have read and agreed to publish this version of the manuscript.

\section{References}

1. Khoshnamvand N, Ahmadi S, Mostafapour FK. Kinetic and isotherm studies on ciprofloxacin an adsorption using magnesium oxide nanopartices. J. Appl. Pharm. Sci. 2017;7:79-83. doi: 10.7324/JAPS.2017.71112.

2. Polianciuc SI, Gurzău AE, Kiss B, Georgia Ștefan M, Loghin F. Antibiotics in the environment: causes and consequences. Medici. Pharm. Reports 2020;93:231-240. doi: 10.15386/mpr-1742.

3. Anthony ET, Ojemaye MO, Okoh AI, Okoh OO. Potentials of low-cost methods for the removal of antibiotic-resistant bacteria and their genes in low budget communities: A review. J. Water. Proc. Eng. 2021;40:101919. doi:10.1016/j.jwpe.2021.101919.

4. Le T, Ng C, Tran NH, Chen H, Yew-hoong K, Gin Y. Removal of antibiotic residues, antibiotic resistant bacteria and antibiotic resistant genes in municipal wastewater by membrane bioreactor systems. Water Res. 2018;145:498-508. doi: 10.1016/j. watres.2018.08.060.

5. Norabadi E, Panahi AH, Ghanbari R, Meshkinian A, Kamani $\mathrm{H}$, Ashrafi SD. Optimizing the parameters of amoxicillin removal in a photocatalysis/ozonation process using Box-Behnken response surface methodology. Desalin. Water Treat. 2020;192: 234-240. doi: 10.5004/dwt.2020.25728.

6. Nasiri A, Malakootian M, Shiri MA, Yazdanpanah G, Nozari M. CoFe2O4@methylcellulose synthesized as a new magnetic nanocomposite to tetracycline adsorption: modeling, analysis, and optimization by response surface methodology. J. Polym. Res. 2021;28:192. doi: 10.1007/s10965-021-02540-y.

7. Shaipulizan NS, Jamil SNAM, Kamaruzaman S, et al. Preparation of ethylene glycol dimethacrylate (EGDMA)-based terpolymer as potential sorbents for pharmaceuticals adsorption. Polymers 2020;12:423. doi: 10.3390/polym12020423.

8. Zhang YR, Su P, Huang J, Wang QR, Zhao BX. A magnetic nanomaterial modified with poly-lysine for efficient removal of anionic dyes from water. Chem. Eng. J. 2015;262:313-318. doi: 10.1016/j.cej.2014.09.094.

9. Qin P, Huang D, Tang R, Gan F, Guan Y, Lv X. Enhanced adsorption of sulfonamide antibiotics in water by modified biochar derived from bagasse. Open Chemistry 2019;17:13091316. doi: 10.1515/chem-2019-0141.

10. Sulyman M, Namiesnik J, Gierak A. Low-cost adsorbents derived from agricultural by-products/wastes for enhancing contaminant uptakes from wastewater: A review. Polish J. Environ. Stud. 2017;26:479-510. doi: 10.15244/pjoes/66769.

11. Inyang MI, Gao B, Yao Y, et al. A review of biochar as a low-cost adsorbent for aqueous heavy metal removal. Crit. Rev Environ. Sci. Technol. 2016;46:406-433. doi: 10.1080/10643389.2015. 1096880.

12. Braghiroli FL, Bouafif H, Neculita CM, Koubaa A. Activated Biochar as an Effective Sorbent for Organic and Inorganic Contaminants in Water. Water Air Soil Pollut. 2018;229:230. doi: 10.1007/s11270-018-3889-8.

13. Krasucka P, Pan B, Sik Ok Y, Mohan D, Sarkar B, Oleszczuk P. Engineered biochar - A sustainable solution for the removal of antibiotics from water. Chem. Eng. J. 2021;405:126926. doi: 10.1016/j.cej.2020.126926.

14. Oliveira FR, Patel AK, Jaisi DP, Adhikari S, Lu H, Khanal SK. Environmental application of biochar: Current status and perspectives. Bioresour. Technol. 2017;246:110-122. doi: 10.1016/j.biortech.2017.08.122.

15. Zhao JJ, Shen XJ, Domene X, Alcañiz JM, Liao X, Palet C. Comparison of biochars derived from different types of feedstock and their potential for heavy metal removal in multiple-metal solutions. Sci. Rep. 2019;9:1-12. doi: 10.1038/s41598-019-46234-4.

16. Thompson KA, Shimabuku KK, Kearns JP, Knappe DRU, Summers RS, Cook SM. Environmental Comparison of Biochar and Activated Carbon for Tertiary Wastewater Treatment. Environ. Sci. Technol. 2016;50:11253-11262. doi: 10.1021/acs. est.6b03239.

17. Noer Hidayat D, Maming M, Liong S. Utilization of Chicken Feather Biomass As Metal Zinc Adsorbent (Zn2+). J. Akta Kimia Indonesia (Indonesia Chimica Acta) 2019;10:11. doi: 10.20956/ica.v10i2.6651.

18. Li Z, Reimer C, Picard M, Mohanty AK, Misra M. Characterization of Chicken Feather Biocarbon for Use in Sustainable Biocomposites. Front. Mater. 2020;7:1-12. doi: 10.3389/fmats.2020.00003.

19. Cuixia Y, Yingming X, Lin W, Xuefeng L, Yuebing S, Hongtao J. Effect of different pyrolysis temperatures on physico-chemical characteristics and lead(II) removal of biochar derived from chicken manure. RSC Adv. 2020;10:3667-3674. doi: 10.1039/ c9ra08199b.

20. Rangabhashiyam S, Balasubramanian P. The potential of lignocellulosic biomass precursors for biochar production: Performance, mechanism and wastewater application - A review. Ind. Crops Prod. 2019;128:405-423.

21. Dai Y, Zhang N, Xing C, Cui Q, Sun Q. The adsorption, regeneration and engineering applications of biochar for removal organic pollutants: A review. Chemosphere 2019;223:12-27.

22. El-Wakeel ST, El-Tawil RS, Abuzeid HAM, Abdel-Ghany AE, Hashem AM. Synthesis and structural properties of MnO2 as adsorbent for the removal of lead $(\mathrm{Pb} 2+)$ from aqueous solution. J. Taiwan Inst. Chem. Eng. 2017;72:95-103. doi: 10.1016/j.jtice. 2017.01.008.

23. Zhang H, Xu F, Xue J, Chen S, Wang J, Yang Y. Enhanced removal of heavy metal ions from aqueous solution using manganese dioxide-loaded biochar: Behavior and mechanism. Sci. Rep. 2020;10:1-13. doi: 10.1038/s41598-020-63000-z. 
24. Nouh ESA. Manganese oxide-coated wool as adsorbent for U(VI) removal from aqueous waste solutions. Int. J. Environ. Analyt. Chem. 2020;7319:1-14. doi: 10.1080/03067319.2020.1751834.

25. Adeyi AA, Aberuaga F. Comparative Analysis of Adsorptive Desulphurization of Crude Oil by Manganese Dioxide and Zinc Oxide. Res. J. Chem. Sci. 2012;2:14-20.

26. Adeyi AA, Popoola LT, Yusuff AS, Grema AS. Kinetics Analysis and Dosage Effects of Manganese Dioxide Adsorbent on Desulphurization of Crude Oil. J. Biopro. Chem. Eng. 2014;2:1-6.

27. Li J, Cai X, Liu Y, et al. Design and Synthesis of a Biochar-Supported Nano Manganese Dioxide Composite for Antibiotics Removal From Aqueous Solution. Front. Environ. Sci. 2020;8:1-12. doi: 10.3389/fenvs.2020.00062.

28. Ho YS. Review of second-order models for adsorption systems. J. Hazard. Mater. 2006;136:681-689. doi: 10.1016/j.jhazmat. 2005.12.043.

29. Dahri MK, Kooh MRR, Lim LBL. Application of Casuarina equisetifolia needle for the removal of methylene blue and malachite green dyes from aqueous solution. Alexandria Eng. J. 2015;54:1253-1263. doi: 10.1016/j.aej.2015.07.005.

30. Weber WJ, Morris JC. Kinetics of Adsorption on Carbon from Solution. J. Sanit. Eng. Div. 1963;89:31-60.

31. Magdy YM, Altaher H, ElQada E. Removal of three nitrophenols from aqueous solutions by adsorption onto char ash: equilibrium and kinetic modeling. Appl. Water. Sci. 2018;8:26. doi: 10.1007/ s13201-018-0666-1.

32. Turk Sekulic M, Boskovic N, Milanovic M, Grujic Letic N, Gligoric E, Pap S. An insight into the adsorption of three emerging pharmaceutical contaminants on multifunctional carbonous adsorbent: Mechanisms, modelling and metal coadsorption. J. Mol. Liq. 2019;284:372-382. doi: 10.1016/j.molliq.2019.04.020.

33. Ciobanu G, Harja M. Studies on the sorption of levofloxacin from aqueous solutions onto nanohydroxyapatite. Revue Roumaine de Chimie 2018;63:593-601.

34. Viana F, Dutra A, Pires BC, Nascimento TA. Functional polyaniline / multiwalled carbon nanotube composite as an efficient adsorbent material for removing pharmaceuticals from aqueous media. J. Environ. Manag. 2018;221:28-37. doi: 10.1016/j. jenvman.2018.05.051

35. Mishra AK, Agrawal NR, Das I. Synthesis of water dispersible dendritic amino acid modified polythiophenes as highly effective adsorbent for removal of methylene blue. J. Environ. Chem. Eng. 2017;5:4923-4936. doi: 10.1016/j.jece.2017.09.017.

36. Huang Z, Li Y, Chen W, et al. Modified bentonite adsorption of organic pollutants of dye wastewater. Mat. Chem. Phys. 2017;202:266-276. doi: 10.1016/j.matchemphys.2017.09.028.

37. Saruchi, Kumar V. Adsorption kinetics and isotherms for the removal of rhodamine $\mathrm{B}$ dye and $\mathrm{Pb}^{+2}$ ions from aqueous solutions by a hybrid ion-exchanger. Arabian J. Chem. 2019;12:316-329. doi: 10.1016/j.arabjc.2016.11.009.

38. Brouers F, Al-Musawi TJ. On the optimal use of isotherm models for the characterization of biosorption of lead onto algae. J.
Mol. Liq. 2015;212:46-51. doi: 10.1016/j.molliq.2015.08.054. 39. Davoudinejad M, Ghorbanian SA. Modeling of adsorption isotherm of benzoic compounds onto GAC and introducing three new isotherm models using new concept of Adsorption Effective Surface (AES). Sci. Res. Ess. 2013;8:2263-2275. doi: 10.5897/ SRE10.643.

40. You D, Min X, Liu L, et al. New insight on the adsorption capacity of metallogels for antimonite and antimonate removal: From experimental to theoretical study. J. Hazard. Mater. 2018;346:218-225. doi: 10.1016/j.jhazmat.2017.12.035.

41. Zhao X, Yi S, Dong S, Xu H, Sun Y, Hu X. Removal of levofloxacin from aqueous solution by magnesium-impregnated biochar: Batch and column experiments. Chem. Speciat. Bioavail. 2018;30:68-75. doi: 10.1080/09542299.2018.1487775.

42. Limbikai SS, Deshpande NA, Kulkarni RM, Khan AAP, Khan A. Kinetics and adsorption studies on the removal of levofloxacin using coconut coir charcoal impregnated with $\mathrm{Al} 2 \mathrm{O} 3$ nanoparticles. Desalin. Water. Treat. 2016;57:23918-23926. doi: 10.1080/19443994.2016.1138330.

43. Jalil MER, Baschini M, Sapag K. Removal of ciprofloxacin from aqueous solutions using pillared clays. Materials 2017;10:17-19. doi: 10.3390/ma10121345.

44. Chaturvedi G, Kaur A, Umar A, Khan MA, Algarni H, Kansal K. Removal of fluoroquinolone drug, levofloxacin, from aqueous phase over iron based MOFs, MIL-100(Fe). J. Solid State Chem. 2020;281:121029. doi: 10.1016/j.jssc.2019.121029

45. Danalıoğlu ST, Kerkez Kuyumcu Ö, Abdel Salam M, Bayazit ŞS. Chitosan grafted $\mathrm{SiO}_{2}-\mathrm{Fe}_{3} \mathrm{O}_{4}$ nanoparticles for removal of antibiotics from water. Environ. Sci. Pollut. Res. 2018;25: 36661-36670. doi: 10.1007/s11356-018-3573-y.

46. de Sousa DNR, Insa S, Mozeto AA, Petrovic M, Chaves TF, Fadini PS. Equilibrium and kinetic studies of the adsorption of antibiotics from aqueous solutions onto powdered zeolites. Chemosphere 2018;205:137-146. doi: 10.1016/j.chemosphere. 2018.04.085.

47. Sun $\mathrm{X}, \mathrm{Hu} \mathrm{D}$, Yang L-Y, Wang N, Wang YG, Ouyang X-K. Efficient adsorption of Levofloxacin from aqueous solution using calcium alginate/metal organic frameworks composite beads. J. Sol-Gel Sci. Technol. 2019;91:353-363. doi: 10.1007/ s10971-019-05001-7.

48. Elamin MR, Abdulkhair BY, Algethami FK, Khezami L. Linear and nonlinear investigations for the adsorption of paracetamol and metformin from water on acid-treated clay. Sci. Rep. 2021;11:1-13. doi: 10.1038/s41598-021-93040-y.

49. Asif Tahir M, Bhatti HN, Iqbal M. Solar Red and Brittle Blue direct dyes adsorption onto Eucalyptus angophoroides bark: Equilibrium, kinetics and thermodynamic studies. J. Environ. Chem. Eng. 2016;4:2431-2439. doi: 10.1016/j.jece.2016.04.020.

50. Saha P, Chowdhury S, Gupta S, Kumar I. Insight into adsorption equilibrium, kinetics and thermodynamics of Malachite Green onto clayey soil of Indian origin. Chem. Eng. J. 2010;165:874-882. doi: 10.1016/j.cej.2010.10.048. 